\title{
Assessing the potential of INFFER to improve management of agro-environmental assets in Tuscany
}

\author{
G. Cesare Pacini, ${ }^{1}$ Leonardo Gabellini, ${ }^{1}$ Anna M. Roberts, ${ }^{2}$ Concetta Vazzana, ${ }^{1}$ \\ Geoff Park, ${ }^{2}$ David J. Pannell ${ }^{2}$ \\ 'Dipartimento di Scienze delle Produzioni Agroalimentari e dell'Ambiente, Università di Firenze, \\ Italy; ${ }^{2}$ Future Farm Industries Co-operative Research Centre, University of Western Australia, \\ Crawley, Australia
}

\begin{abstract}
In the European Union, as in many parts of the world, there is increasing pressure to demonstrate that environmental projects achieve expected outcomes and are cost-effective. This paper reports on a trial application of an environmental investment framework, the Investment Framework for Environmental Resource (INFFER). The framework, based on benefit:cost analysis principles, was applied to agro-environmental assets in the Mugello and Valdisieve areas of northern Tuscany, Italy. Farmers, environmental and institutional representatives and technical experts took part in the process of identifying agro-environmental assets in the region. A total of 26 assets were identified, and of these, only 2 (the last remaining population of Cistus laurfolius within the natural protected area of local interest (Area Naturale Protetta di Interesse Locale, ANPIL) of Santa Brigida, and the Sant' Antonio forest were selected as having reasonable prospects of progressing to cost-effective projects (benefit:cost ratio $>1$ ). Detailed projects were developed for both assets and found to be cost-effective based on available information. While the mindset of being clear about
\end{abstract}

Correspondence: G. Cesare Pacini, Dipartimento di Scienze delle Produzioni Agroalimentari e dell'Ambiente, Università di Firenze, Italy.

E-mail: gaiocesare.pacini@unifi.it

Key words: land management, INFFER, project assessment, agro-environmental measures, Natura 2000.

Conference presentation: SIA XLI Congress, Bari, 2012.

Acknowledgements: we acknowledge the support given by Bianca Maria Del Monte and Tony Ventre of the Union of Municipalities of Valdarno and Valdisieve, in completing the project assessment form of S. Antonio, and Gianna Piccardi, Municipality of Pontassieve, and Prof. Paolo Grossoni, University of Florence, in completing the project assessment form of $\mathrm{S}$. Brigida.

Received for publication: 7 June 2013.

Revision received: 17 August 2013.

Accepted for publication: 21 September 2013.

(C) Copyright G.C. Pacini et al., 2013

Licensee PAGEPress, Italy

Italian Journal of Agronomy 2013; 8:e27

doi:10.4081/ija.2013.e27

This article is distributed under the terms of the Creative Commons Attribution Noncommercial License (by-nc 3.0) which permits any noncommercial use, distribution, and reproduction in any medium, provided the original author(s) and source are credited. identifying and valuing natural assets was a new concept to participants, overall the process worked well. The factors considered in calculating a benefit:cost ratio, including technical feasibility, adoption and compliance factors, socio-political risks, costs and the likelihood of obtaining long-term funding to maintain project benefits, were all relevant in Tuscany and required the knowledge of local experts. Overall, INFFER appears relevant and useful in an EU context, and, in particular, is highly compatible with the EU Natura 2000 nature and biodiversity policy.

\section{Introduction}

Sustainable management of agro-ecosystems has become an increasingly important feature of EU funding programmes. The role of farmers and other land managers as custodians of the countryside is acknowledged and the EU common agricultural policy (CAP) has progressively allocated higher public funding for rural development measures, including agro-environmental support. At the beginning of the programming period, $42 \%$ of the total EU 2007-2013 budget (at 2004 prices) was allocated to agriculture. Of this, 19\% (corresponding to approx. 70 billion Euros, later increased to $24 \%$ ) was intended for rural development programmes (RDP) and the rest for policy on markets and direct aid (European Commission, 2007). Italy is the first ranked EU country for public expenditure on rural development [i.e. funding from the EU European Agricultural Fund for Rural Development (EAFRD) plus Member State contributions] for the period 2007-20013 (17.6 billion Euros). The largest share of the Italian budget (i.e. 41\%) is devoted to Axis 2, Improving the environment and the countryside, which includes all the so-called agro-environmental measures forming the second pillar of the RDP (European Network for Rural Development, 2013).

The earliest substantial development of agro-environmental measures occurred in Europe in the 1980s with a number of national initiatives in individual member states and in European Free Trade Association countries. Agro-environmental measures have become a central feature of the EU CAP since the mid-1990s, the guiding principle of which is that farmers are rewarded for providing significant environmental benefits to the society. This principle has been reinforced following the Agenda 2000 and the 2003 CAP reform agreements, together with the introduction of cross-compliance and good agricultural and environmental practice requirements to be eligible for direct aid in the form of single farm payments. Agro-environmental measures were merged with other RDP measures as part of the Agenda 2000 reform from 2000-2006, which has continued in the current 2007-2013 programming period (Lampkin, 2011).

In Europe, as in other parts of the world, there is increased pressure to show that environmental outcomes are being achieved from public 
spending. The report by the European Court of Auditors (2011) underlines the fact that EU programme objectives are not specific enough for them to be assessed to see whether they are achievable or not. Furthermore, the report states that no clear justification for current agro-environmental payments is provided and that very little information is available on the benefits achieved. The report recommends the need for increased targeting, greater focus on payments to address specific environmental problems, and greater use of evidence to support management decisions.

Cooper et al. (2009) argue that while the EU agro-environmental and cross-compliance measures have succeeded in stemming decline in several areas of provision of public resources, there is a need for clearer targets to be set and for measures to be more cost-effective. We also need to learn from some of the more innovative, smaller-scale programmes. According to Schomers and Matzdorf (2013), who reviewed 457 articles on payments for ecosystem services in developing and industrialised countries, poor or lack of targeting is a common problem of government payment programmes. Supporting evidence is cited with examples from Costa Rica, Mexico, China, South Africa, and Brazil, and also includes other examples of agro-environmental programmes almost all of which are in the European Union and the USA. While Schomers and Matzdorf did not consider programmes in Australia, a previous analysis by Pannell and Roberts (2010) supports the need for improved targeting and demonstration of cost-effectiveness.

The Natura 2000 network of protected areas provides an example of one of the most specific environmental programmes in the EU. It began in 1992 with the aim of protecting the most seriously threatened habitats and species across Europe. Natura 2000 provides the largest network of protected areas in the world. Despite its importance, the corresponding 2007-2012 allocations for payments in the agricultural and forestry sectors were only $1.2 \%$ of the entire allocation of Axis 2 at EU level (European Commission, 2012). In addition to the small allocation overall, within the Region of Tuscany, Italy, no Natura 2000 payments have been made. This has been in part due to the difficulty in assessing the costs and/or incomes lost by farmers and foresters, as well as the management constraints faced in these areas (Regione Toscana, 2012). Given that Natura 2000 measures have also not been implemented in 13 of the $27 \mathrm{EU}$ member states, it is highly probable that these problems are also being faced in many other EU regions.

Few tools are available to assess environmental, economic and social costs and benefits of locally targeted agro-environmental measures, and to help decision makers choose sound implementation projects. Procedural tools for assessing sustainability of projects, plans, programmes, regulations and policies, such as environmental impact assessment (EIA), strategic environmental assessment, and impact assessment (IA) and sustainability impact assessment (SIA) [Organisation for Economic Co-operation and Development (OECD), 2010 ], tend to be high level and are not really useful at the design stage. A review of such tools is outlined elsewhere (Institute for Environmental Studies, 2006). Even the most well developed and institutionalised framework, the EIA, is criticised as being only marginally useful, with limited influence on decision making and cumbersome bureaucratic procedures (Cashmore et al., 2004; Nilsson, 2006). Furthermore, it mainly addresses the environmental dimension of sustainability. EIA reports have not paid much attention to the socio-economic impact (Chadwick, 2002; Kørnøv et al., 2005; Buytaert, 2011). The EU IA and the OECD SIA do cover social and economic aspects, but only on a high level and they are still poorly suited to local agro-environmental management projects and measures.

Given the need for EU programmes to become both more focused on outcome and cost-effective, and the lack of available operational tools, this paper assesses the suitability of using a framework developed by an inter-disciplinary team in Australia: the Investment Framework for
Environmental Resources (INFFER ${ }^{\mathrm{TM}}$ ) (http://www.inffer.org; Pannell et al., 2012). It provides a structured approach based on benefit:cost analysis principles for developing and prioritising projects to address environmental issues to achieve cost-effective environmental outcomes. While it has been developed and tested extensively in Australia, because of its sound theoretical underpinnings (Pannell et al., 2013; Alexander et al., 2010 ) it is likely to have broad international application.

This paper presents the results of the first INFFER trial in Europe where the process has been applied in 2 case-study areas in Tuscany: Mugello and Valdisieve. We discuss whether INFFER has the potential to support the design of public investment programmes for the management of agro-environmental assets in the EU, particularly for Natura 2000. A comment on the usefulness and need for an asset-based approach as a response to ineffective public investment can be found in Alexander et al. (2010). Assets are defined as areas (places) within the natural environment of significant value. An asset is a place to be protected, improved or better managed through a proposed project. It is spatially defined and could be large or small, degraded or pristine, localised or dispersed. Selected assets for detailed INFFER application in the present study were endangered Cistus laurifolius population in the natural protected area of local interest (Area Naturale Protetta di Interesse Locale, ANPIL, Tuscany Region Law no. 49/1995) Poggio Ripaghera, Santa Brigida e Valle dell'Inferno (henceforth named S. Brigida) and Natura 2000 habitats in the regional forest complex of Sant'Antonio (henceforth named S. Antonio).

\section{Materials and methods}

\section{INFFER}

INFFER consists of a 7-step process, which begins with identifying spatial and significant agro-environmental assets (Step 1), filtering assets to identify candidates for detailed assessment (Step 2), and use of the project assessment form (PAF, Step 3). Steps 4-7 address project selection, implementation, monitoring, evaluation and adaptive management. In this paper we address Steps 1-3 (Figure 1).

There are three fundamental features that need to be understood by anyone involved in the INFFER process, including those participating directly (such as local technical experts and farmers) and decision makers (such as project funders and policy-makers): i) being clear about what is being protected, i.e. the agro-environmental asset; ii) identifying the threats faced by the asset; iii) being able to develop a specific, measurable, achievable, realistic and time-bound (SMART) goal.

Defining projects based on protecting agro-environmental assets helps people think clearly about what is required to achieve outcomes. The outcome-focused project is designed around the asset and the SMART goal(s). The information collected in Step 3 is the core of INFFER and provides the basis for assessing whether the project is costeffective (value for money), as calculated by the benefit:cost ratio (BCR). The BCR algorithm is:

$$
B C R=\frac{V \times W \times A \times B \times F \times P \times G \times D F}{C+P V_{M+E} \times G}
$$

where:

$V$ is the value that is placed on the asset. Benefit:cost analysis requires benefits to be calculated and thus the value of agro-environmental assets must be evaluated because without this the environmental benefits of projects cannot be assessed. Whilst complex non-market valua- 
tion or other approaches can be used, these are rarely available, as is the case for the assets in Tuscany. Because asset value is only one factor in the BCR, and in the absence of other non-market valuation information, INFFER uses a simple value assessment based on expert knowledge. Assets are commonly ranked on a scale between 1 and 100. For those interested in converting $\mathrm{V}$ scores to monetary values, a $\mathrm{V}$ score of 1 equates to a monetary value of 20 million of currency (Pannell et al., 2013), in this case, Euros.

Besides the factors associated with costs, remaining factors are expressed as probabilities: $W$ is the effectiveness of works; $A$ is the adoption rate by private land managers; $B$ represents the risk of adoption of adverse practices; $F$ is the technical feasibility risk; $P$ represents socio-political risks; $G$ is the probability of obtaining long-term funding; $D F$ is the discount factor; $C$ is the project cost in million Euros; $P V$ is the sum of the present value over project duration of annual maintenance cost $(M)$ and polluter-pays compliance costs $(E)$.

Projects with BCR values over 1 indicate cost-effective investments. Information about the rationale for the BCR algorithm and the underpinning theoretical background can be found in Pannell et al. (2012, 2013).

\section{Selection of case-study areas}

We initially selected the Mugello area of Tuscany as the case-study region. It is similar to many areas in Europe, having multiple and sometimes conflicting land uses including agriculture, transportation, tourism and nature conservation. We subsequently extended the casestudy region to include Valdisieve because few assets identified in Mugello were assessed as suitable to progress to the project development (Step 3) stage, without which we could not assess the usefulness of INFFER.

The Mugello basin is located approximately $30 \mathrm{~km}$ north of Florence, northern Tuscany (latitude $44^{\circ} \mathrm{N}$ ). Valdisieve is the part of the Sieve river valley from Mugello, where the River Sieve originates, to the town of Pontassieve, where the Sieve joins the River Arno, approximately 15 $\mathrm{km}$ east of Florence. These areas have a temperate climate with an orographic rain regime and a mean annual rainfall of $1000 \mathrm{~mm}$. While the northern area of the Province of Florence, where Mugello and Valdisieve are located, has a prevailing mountain economy, Mugello and Valdisieve themselves are located within rural areas with high tourism and valuable natural features. Within the last decade, a large transport infrastructure project was started in the form of a high-speed train line linking southern with northern Italy. This has increased the pressure for conflict over land use between rural, residential and industrial settlements.

\section{Application of INFFER in Mugello and Valdisieve}

\section{Identification of asset}

Important assets for the Mugello area were identified through two separate focus groups, one with farmers, and another representing local institutions which included representatives from farmers' and environmental organisations and public administration officials. The farmers' and institutional focus groups were made up of 13 and 9 members, respectively, including 3 researchers who acted as facilitators in both groups. Selection criteria for focus group composition were based on those identified by Noble (2004) to ensure SEA quality assurance. They were: i) representation of those potentially affected by the project (affected interest groups, affected sectors and government departments); ii) representation of those who affect project development (public administrators, planners and policy-makers); iii) appropriate geographical representation; iv) input from individuals with the appropriate expertise and experience; v) feasibility given available time and resources; vi) credibility of panel size and membership.

Table 1 provides a summary of the makeup of the focus groups involved.

The institutional focus group meeting took place after that of the farmers' focus group. At this second meeting, the assets identified by the farmers' group were presented to institutional participants. Institutional participants suggested additional assets they thought important. Each participant indicated a number of potential assets that were then discussed by the group and subsequently located on a map.

Because Mugello and Valdisieve are areas next to each other with similar characteristics, rather than conduct additional focus group meetings, we asked expert officials of the Union of Municipalities of Valdarno and Valdisieve (authority delegated by the Region of Tuscany to manage the agro-environmental resources of the area) to expand and validate the Mugello asset list. Many assets had previously been identified, e.g. the Sieve river and nesting birds. Seven additional agroenvironmental assets were identified in Valdisieve.

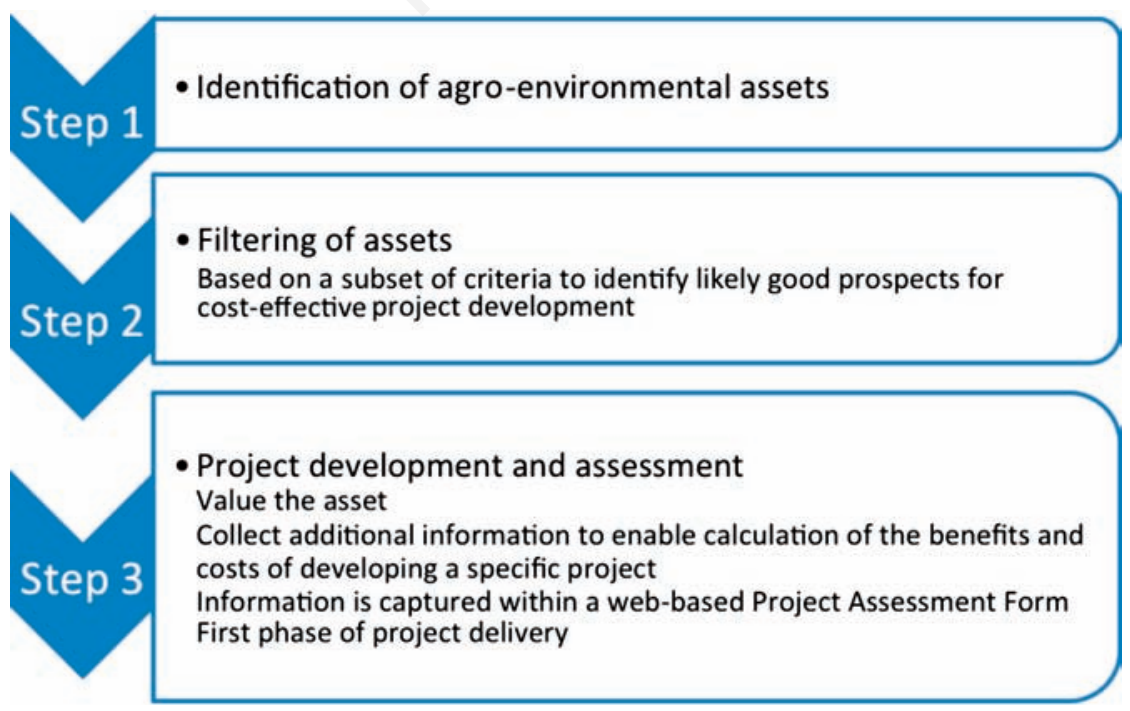

[page 226]
Figure 1. Steps of asset identification, filtering and project assessment in the Investment framework for Environmental Resources (INFFER). 


\section{Filtering of assets}

A set of simple criteria was used to identify potentially cost-effective candidate assets for investment, called 'filtering'. This application used the standard filtering questions developed by INFFER. The filtering questions used for this application were: i) Is the agro-environmental asset clearly identified (spatially-specific, able to be drawn on a map)? ii) Is it possible to set a SMART goal? iii) Is there evidence that management actions will make a difference? iv) If the desired management actions are mainly on private land, is it likely that those actions would be reasonably attractive to fully informed land managers when adopted over the required scale? v) If the project requires change by other institutions (e.g. local government, state government departments), is there a good chance that this will occur?

\section{Valuing assets}

Because this was the first application of INFFER attempted in Europe, a hierarchy for valuing assets was required to help place the local assets identified within this system. The Tuscany value (V) table was constructed by the Authors from Florence University using the hierarchy criteria previously developed in Australia. This was based on the fact that the latter appeared to be extremely general in nature and therefore applicable to a large range of diverse contexts. Higher values were assigned to assets belonging to higher spatial-administrative and normative hierarchical levels, e.g. nationally significant assets rank higher than regionally significant assets, and parks rank higher than reserves.

\section{Assessment of projects}

Information needed to assess projects through the PAF was based on available reports (Grossoni and Venturi, 2009; Vannuccini, 2011; Studio D.R.E.A.M. Italia, 2004) and expert opinion. Experts included officials of the institutions managing the assets, as well as academics within the University of Florence. The PAF drafts were reviewed by INFFER personnel to ensure that the projects were internally consistent and that the BCR parameters appeared to be realistic based on the information provided. The PAFs were then modified using appropriate expert input and quality-assured by INFFER personnel.

\section{Sensitivity analysis}

Sensitivity analysis of the BCR results was performed through modifying selected coefficients, most notably $\mathrm{P}$ and $\mathrm{G}$, with the rationale for their selection presented in the following paragraphs. The PAF coefficients in INFFER are a mixture of qualitative coefficients translated into numbers through a sort of fuzzy logic following expert knowledge (W, A, B, F, P, G) and of quantitative coefficients (C, M, E). The quantitative coefficients are usually accepted by those who have to deal with the consequences of project assessment, whereas coefficients based on expert knowledge and interpretation by scientists are more likely to be questioned and debated.

Private adoption of works and actions (A) and compliance by private citizens (B) are based on exact, non-disputable information, e.g. public land managed by a public institution in the case of S. Antonio, nonavailability of policy measures to fund private adoption in the case of $S$. Brigida, or a tangible difference between the two assets in terms of species composition and erodibility (one species under threat of erosion $v s$ a range of well-established species and habitats). For this reason, the coefficients A and B were excluded from those submitted to sensitivity analysis.

All other coefficients based on expert knowledge were considered for sensitivity analysis. Sensitivity analysis applied to impact of works (W) and technical feasibility (F) did not produce notable results, namely that relative project rankings remained the same (data not shown). The coefficients of socio-political risk $(\mathrm{P})$ and the risk related to longterm funding (G) are affected by multiple drivers and not commonly considered by funders in making investment decisions. In addition, they are open to interpretation through different stakeholder perceptions.

The basis of selecting values for sensitivity analysis was based on the default categories users could choose from the PAF template. Parameter values for $\mathrm{P}$ and $\mathrm{G}$ of one category higher and one category lower than the best-estimated values used in each of the PAF analyses were selected as the basis of the sensitivity analysis.

\section{Results}

\section{Identification of assets}

In total, 27 assets were identified, of which 13 were natural protected areas (Table 2). In general, farmers identified assets that supported agricultural production, although some of these were revised as a result of the institutional focus group where broader environmental

Table 1. Composition of two focus groups involved in selection of environmental assets in the Mugello and Valdisieve case-study regions.

\begin{tabular}{|c|c|}
\hline Farmers' focus group & Institutions' focus group (each organisation was represented by a single person) \\
\hline Organic mixed crop-cattle farm & Farmers' organisation (CIA) \\
\hline Mixed crop-livestock farm & Farmers' organisation (Coldiretti) \\
\hline Organic fruit-vegetable farm & Organic farmers' organisation (AIAB) \\
\hline Mixed crop-livestock farm & Department of parks and protected areas, Province of Florence \\
\hline Organic mixed crop-dairy farm & Mountain Union of Mugello's municipalities \\
\hline Agro-tourism olive farm & $\begin{array}{l}\text { Hunting-land management organisation (ATC4), Florence } \\
\text { Departments of land activities and of management of agro-forestry assets of the Union } \\
\text { of Valdarno and Valdisieve's municipalities } \\
\text { Department of environment of Pontassieve's municipality } \\
\text { Private consultancy firm } \\
\text { Local office for Vallombrosa's biodiversity, State Forestry Corps }\end{array}$ \\
\hline
\end{tabular}

CIA, Confederazione Italiana Agricoltori; Coldiretti, Confederazione Nazionale Coltivatori Diretti; AIAB, Associazione Italiana per l'Agricoltura Biologica; ATC4, Ambito Territoriale di Caccia Firenze 4. 
perspectives were discussed. An example of the farmers' perspective was that the rivers and the creek were valued mainly for their ability to supply water, which has been jeopardised from transport infrastructure works in the area. In contrast, the institutional group identified mainly natural areas (made up of protected species habitats and ecological corridors) or farmland areas known to be of high natural value, the only exception being agricultural land to be considered for consolidation.

\section{Filtering of assets}

Assets which were not sufficiently spatially-specific (Table 2, assets marked with $N$ ) were discarded first. Remaining assets were filtered and results are summarised in Table 3 . As we can see, assets commonly failed to pass one or more of the filtering questions, or there was insufficient information to base a project on. Common issues were that assets had already been severely damaged or were under direct threat of large transport infrastructure projects (railways or highways) that had already been approved. In other cases, the requirement for cooperation and coordination between multiple institutions (4 or more) meant that projects were unlikely to be successful. Four assets were considered potentially suitable for PAF assessment: the S. Antonio forest complex, the 2 ANPIL sites of S. Antonio S Brigida and the site of community importance (SCI) (Sito di Importanza Comunitaria, SIC) S. Brigida. Due to the high percentage of overlap between assets, i.e. $80 \%$ for S. Antonio assets and $90 \%$ for S. Brigida assets, only 2 were selected to proceed for project assessment. These were the $\mathrm{S}$. Antonio forest complex and the S. Brigida ANPIL, both of which had relatively simple management arrangements.

\section{Asset values}

The value (V) table developed is shown in Table 4. Both the S. Antonio and the S. Brigida assets have important biodiversity values. The S. Brigida ANPIL is made up of 817 ha of protected natural area of local interest instituted and managed by the Municipality of Pontassieve (Florence, Tuscany). Of the total area of the ANPIL, $84 \%$ is woodland ( $32 \%$ chestnut, $24 \%$ oak, $16 \%$ mixed, and the remaining $12 \%$ made up of other tree species including beech), $12 \%$ is bushland and

Table 2. Assets identified for Mugello and Valdisieve and whether they were sufficiently spatially-specific to be used for an INFFER assessment.

\begin{tabular}{|c|c|}
\hline $\begin{array}{l}\text { Asset identified by } \\
\text { farmer group }\end{array}$ & Description of the asset and its specificity for INFFER \\
\hline Land consolidation & $\begin{array}{l}\mathrm{N}^{*} \text {, rearrangement of land parcels and corresponding ownership to form larger and more contiguous land holdings; } \\
\text { for farmers, the way in which land is arranged is an asset itself; although single land parcels can be specifically identified on } \\
\text { a map, the way in which they are rearranged cannot be unequivocally identified. While land consolidation is an important issue } \\
\text { for farmers, it cannot easily be described as a spatially-specific asset. }\end{array}$ \\
\hline Agro-ecosystem continuity & $\begin{array}{l}\mathrm{N} \text {, uninterrupted connection, succession, or union of agro-ecosystems; farmers referred to the importance of } \\
\text { agro-ecosystems not being interrupted by alternative land uses like civil settlements and transport infrastructure; although } \\
\text { single agro-ecosystem types could be specifically identified on a map, the levels of connectivity could not be presented. }\end{array}$ \\
\hline Grasslands & $\begin{array}{l}\mathrm{N} \text {, while grasslands carry out important ecosystem functions and can be identified on a map, grassland types were } \\
\text { heterogeneous in terms of threat and ability to protect. Without further work to define areas more clearly, they were deemed } \\
\text { unlikely to be suitable to progress to project assessment. }\end{array}$ \\
\hline $\begin{array}{l}\text { Ecological infrastructure } \\
\text { networks }\end{array}$ & $\begin{array}{l}\text { N, strategically planned and managed networks of natural lands, other open spaces and water bodies that conserve } \\
\text { ecosystem functions and provide associated benefits to society; although they could in theory be identified on a map, } \\
\text { they were not sufficiently well-described by farmers. }\end{array}$ \\
\hline $\begin{array}{l}\text { Land (protected against } \\
\text { urbanisation) }\end{array}$ & $\begin{array}{l}\mathrm{N} \text {, although land threatened by urbanisation could potentially be located on a map, } \\
\text { this was not done in the focus group exercise. }\end{array}$ \\
\hline Drainage system networks & $\mathrm{N}$, similar issue as for land and agro-ecosystem continuity assets. \\
\hline Sieve river & $\mathrm{Y}^{\circ}$, the whole river was identified as the asset. \\
\hline Santerno river & Y, the whole river was identified as the asset. \\
\hline Rovigo creek & Y, the whole creek was identified as the asset. \\
\hline $\begin{array}{l}\text { Asset identified by } \\
\text { institutional group }\end{array}$ & Specificity for INFFER and description \\
\hline
\end{tabular}

Natural protected areas

Y, these include natural protected areas of local interest (Aree Naturali Protette di Interesse Locale, ANPIL,

Tuscany Region Law n. 49/1995), Habitats Directive Sites of Community Importance (SCI) (Siti di Importanza Comunitaria, SIC, Tuscany Region Law n. 56/2000, Regional Government Resolution n. 644/2004), natural reserves and forest complexes of special natural relevance; there were 13 in the case-study areas and all could be identified on a map; the whole of a natural protected area could represent an asset or just a component (e.g. endangered Cistus laurifolius population in the S. Brigida ANPIL).

Ecological corridors $\quad \mathrm{N}$, similar issue as for land and agro-ecosystem continuity assets.

Pastures and grazing systems $\quad \mathrm{N}$, similar issue as for grasslands.

Habitats of nesting birds $\quad \mathrm{N}$, in theory habitats can be indicated on a map, but this was not done.

Land consolidation $\quad \mathrm{N}$, see above.

Habitats of wolf $\quad \mathrm{N}$, although wolf habitats are potentially spatially-identifiable, there was a lack of information on their relevance for the case-study areas; wolf sightings are on the increase but have not been traced with enough detail to determine habitats spatially.

${ }^{*} \mathrm{~N}$, not sufficiently spatially-specific to be used for an INFFER project assessment. These areas often covered most of the case-study area or while known to be important (e.g. wolf), there was not enough information to allow participants to identify specific areas of significance; ${ }^{\circ} \mathrm{S}$, sufficiently spatially-specific, area(s) could be indicated on a regional map. 
4\% pastureland. The most valuable wild species (in terms of rarity) within the asset is the laurel-leaf cistus (or laurel-leaved rock rose, Cistus laurifolius); S. Brigida is the last remaining site of this species in Italy. For the purpose of the present study, the endangered Cistus laurifolius population in the ANPIL S. Brigida was defined as the agroenvironmental asset, occupying 23.7 ha of the ANPIL area.

The second asset evaluated was the Natura 2000 habitats in the S. Antonio Forest. The S. Antonio Forest is a complex of 1100 ha of woodland, at an average 950-1000 m asl, located in the Municipality of Reggello (Florence, Tuscany). It is owned by the Region of Tuscany and is managed by the Union of Municipalities of Valdarno and Valdisieve. The S. Antonio Natura 2000 habitats are Asperulo-Fagetum beech forests, Castanea sativa chestnut forests, Apennine beech forests with Abies alba, Apeninne beech forests with Taxus and Ilex, European dry heaths, Juniperus communis formations on heaths or calcareous grasslands, species-rich Nardus grasslands on siliceous substrates in mountain areas, and hydrophilous tall herb fringe communities.

$A V$ value of 2 was selected for both the assets. The rationale was that both assets were part of an ANPIL $(0.1<\mathrm{V}<2$, Table 4$)$ and of an SCI
$(2<\mathrm{V}<5)$. While the $\mathrm{S}$. Antonio site was larger (all things being equal this would imply a higher $V$ value than for $S$. Brigida), the rarity of the Cistus laurifolius within S. Brigida was the reason for a comparable V score.

\section{Project assessment}

Detailed PAFs were completed for each asset. Table 5 shows the BCR values and corresponding coefficients. Both projects appeared cost effective (BCR of S. Antonio 3.3 and 2.0 for S. Brigida). In general, most of the parameters of the BCR numerator, except for the discount factor for time lags (coefficient $\mathrm{DF}_{\mathrm{L}}$ ), were higher for S. Antonio, which increased the overall benefits of that project. However, the costs (i.e. denominator) were also higher for S. Antonio, reducing the BCR compared with value if the costs had been the same for both. The largest differences in individual parameters were related to adoption and compliance by private landholder and citizens (coefficients A and B, respectively), socio-political and long-term funding risks ( $\mathrm{P}$ and $\mathrm{G}$, respectively), and project and maintenance costs (C and $\mathrm{M}$, respectively). Possible explanations for the differences between BCR parameters are

Table 3. Results of INFFER filtering for Mugello and Valdisieve assets (assets not spatially-specific had already been previously discarded).

\begin{tabular}{ll} 
Asset & Result of filtering \\
Sieve river & Discarded, lack of information to develop a quality project \\
Santerno river & Discarded, damage level high, failed questions 2 and 3, thus unlikely to lead to a cost-effective project \\
\hline Rovigo creek & Discarded, damage level high, failed questions 2 and 3 \\
SCI* Raticosa & Discarded, lack of information to develop a quality project \\
\hline SCI Monte Beni & Discarded, damage level high, failed questions 2 and 3 \\
SCI Firenzuola & Discarded, damage level high, failed questions 2 and 3 \\
\hline SCI Giogo & Discarded, damage level high, failed questions 2 and 3 \\
SCI Calvana & Discarded, administration procedures likely to be problematic, failed question 5 \\
\hline SCI Monte Morello & Discarded, damage level high, failed questions 2 and 3 \\
Sant’Antonio forest & Proceed to PAF, sufficient information for detailed analysis \\
\hline ANPIL ${ }^{\circ}$ S. Antonio & $80 \%$ overlap with S. Antonio forest \\
SCI Vallombrosa-S. Antonio & $50 \%$ overlap with S. Antonio forest, problematic administration procedures, failed question 5 \\
\hline Vallombrosa reserve & $50 \%$ overlap with SCI Vallombrosa-S. Antonio, problematic administration procedures, failed question 5 \\
S.Brigida ANPIL & Proceed to PAF, sufficient information for detailed analysis \\
\hline SCI S. Brigida & $90 \%$ overlap with S. Brigida ANPIL \\
Le Balze NPALI & Discarded, lack of information to develop a quality project \\
\hline
\end{tabular}

*Habitats Directive's Site of Community Importance (SCI) (Sito di Importanza Comunitaria, SIC); ${ }^{\circ}$ atural protected area of local interest (Area Naturale Protetta di Interesse Locale, ANPIL).

Table 4. Scale used to estimate $\mathrm{V}$ values of Tuscan assets on which to provide a basis for valuing assets identified in this study.

\begin{tabular}{lll}
\hline Asset significance & Asset type (example in brackets) & V value \\
International significance & UNESCO site (Val d'Orcia) & 100 \\
National significance & National Parks (Archipelago of Tuscany, Parco Foreste Casentinesi) & 50 to 100 \\
\hline Very high level significance & National Reserves of Tuscany (Camaldoli, Vallombrosa, Abetone) & 25 to 40 \\
High level significance & Regional Parks (Regional parks of Maremma, Alpi Apuane, San Rossore) & 15 to 25 \\
\hline Moderate level significance & Provincial Parks (Provincial park of mountains in the Livorno area) & 5 to 15 \\
& Whole rivers (Sieve) & 2 to 5 \\
Regional (catchment) significance & SRIs, ${ }^{*}$ SCIs, ${ }^{\circ}$ SPAs, ${ }^{\circ}$ lakes (Bilancino) and wetlands \\
& River reaches of particular high value (economic, ecological or social) & \\
\hline Local significance & ANPIL ${ }^{\#}$ (Poggio Ripaghera, S. Brigida and Valle dell'Inferno) & \\
& Oases (WWF Gabbianello's Oasi) & \\
& River reaches of interest for local community (Santerno) & 0.1 to 2 \\
\hline *Sites of Regional Interest (SRI) (Siti di Interesse Regionale, SIR); ${ }^{\circ}$ Sites of the Natura 2000 network; Natura 2000 sites include the Habitats Directive Sites of Community Importance (SCI) (Siti di Importanza \\
Comunitaria, SIC) and the Birds Directive Special Protection Areas (SPA) (Zona di Protezione Speciale, ZPS); ${ }^{*}$ Natural protected areas of local interest (ANPIL) (Aree Naturali Protette di Interesse Locale, ANPIL).
\end{tabular}


summarized in Table 6. Overall, the process was straightforward and worked well. The process demonstrated that both the benefits and costs associated with projects were highly context-specific.

\section{Sensitivity analysis}

Table 7 presents the sensitivity analysis. With regard to P, the BCR remained cost-effective (BCR greater than 1) for both assets. Furthermore, the S. Antonio BCR remained higher even where the $\mathrm{P}$ value of $\mathrm{S}$. Brigida is increased beyond the best-estimate level of 0.62 (BCR increased to 2.74 where $\mathrm{P}$ of 0.85 was used).

In contrast, varying the $G$ value could change the project rankings. Using a $\mathrm{G}$ value of 0.5 , both projects compared with best estimate values ( 0.3 for S. Brigida and 0.7 for S. Antonio) reversed the BCR rankings.
Furthermore, reducing the $\mathrm{G}$ parameter in the S. Brigida assessment from 0.3 to 0.1 resulted in the project becoming non-cost-effective.

\section{Discussion and conclusions}

From our case study application, the INFFER tools seemed to work well in Tuscany. Participants were clearly engaged and seemed to enjoy the process. Some of the concepts, particularly the importance of identifying assets in a sufficiently clear and spatially-specific way, needed explanation and discussion to help understand the mindset required. However, once explained, the concepts translated well into an Italian

Table 5. Results of benefit-cost ratios and corresponding coefficients calculated for S. Brigida and S. Antonio, respectively.

\begin{tabular}{|c|c|c|c|}
\hline Value/coefficient/benefit-cost ratio & S. Brigida & S. Antonio & Difference \\
\hline Asset value (V) & 2 & 2 & $=$ \\
\hline Impact of works (W) & 0.26 & 0.38 & $+46 \%$ \\
\hline Private adoption of works and actions (A) & 0.4 & 1.0 & $+150 \%$ \\
\hline Compliance with best practices by private citizens (B) & 0.7 & 1.0 & $+43 \%$ \\
\hline Technical feasibility (F) & 0.87 & 0.92 & $+6 \%$ \\
\hline Coefficient including socio-political risk (P) & 0.62 & 0.97 & $+56 \%$ \\
\hline Coefficient incl. risk related to long-term funding $(G)$ & 0.3 & 0.7 & $+133 \%$ \\
\hline Time lag to benefits (L) (years) & 6 & 8 & - \\
\hline Discount factor for time lags (DFL) & 0.75 & 0.68 & $-9 \%$ \\
\hline Project cost (C) (million Euros) & 0.135 & 1.342 & $+894 \%$ \\
\hline Annual maintenance cost (M) (million Euros) & 0.013 & 0.079 & $+508 \%$ \\
\hline Polluter-pays compliance cost (E) (million Euros) & 0 & 0 & $=$ \\
\hline Benefit-cost ratio (BCR) & 2.0 & 3.3 & $+65 \%$ \\
\hline
\end{tabular}

Table 6. Summary of explanations for differences between S. Brigida and S. Antonio in terms of selected coefficients.

Coefficient Explanation

Private adoption of works and actions (A)

S. Brigida $=0.4$

S. Antonio $=1.0$

Compliance with best practices by private citizens (B)

S. Brigida $=0.7$

S. Antonio $=1.0$

Coefficient including socio-political risk (P)

S. Brigida $=0.62$

S. Antonio $=0.97$

Coefficient incl. risk related to

long-term funding $(G)$

S. Brigida $=0.3$

S. Antonio $=0.7$

Project cost (C) (million Euros) and

annual maintenance cost (M)

(million Euros)

S. Brigida $=0.135$ and 0.013

S. Antonio $=1.342$ and 0.079
S. Brigida is on private land, while S. Antonio is on public land. Private landholders in S. Brigida cannot access Natura 2000 measures because they were not put into force by the Tuscany Rural Development Plan (RDP); current RDP measures to support non-productive investments in the forestry sector are not attractive for private landholders and hence A is low for S. Brigida

C. laurifolius in S. Brigida is highly exposed to human threats (illegal flower collection and motor-cross activities) as indicated by a lower B value, whereas $\mathrm{S}$. Antonio has a range of well-established species and habitats which do not attract illegal activities

Socio-political risks (lower P value) associated with the S. Brigida project are considerably higher than that of S. Antonio due to: i) the major funder of the S. Brigida project, the Tuscany Region, is not the institution with responsibility for the project, this being the Pontassieve Municipality; ii) uncertainty in terms of avaiability of funds by the Regional Government, even in the short term; iii) challenges associated with changing the behaviour of people in relation to previously condoned uses such as motor-cross activities; iv) dependence of the project interventions on volunteer work by private citizens through a non-profit organisation For S. Brigida there is no firm long-term plan, institutional manager or funding in place that can guarantee the project in the future (lower $\mathrm{G}$ value), although there are reasonable prospects of this occurring for part of the budget. For S. Antonio there are higher prospects for the required long-term funding being obtained

The S. Brigida project costs are calculated to be much lower due to the fact that they cover conservation measures of habitats of only one species while the $\mathrm{S}$. Antonio project costs cover measures to preserve a wealth of habitats on a much larger scale (23.7 ha vs 144 ha, respectively) 
context and INFFER could be applied. The way the PAF is structured, including information based on different disciplines, feedback mechanisms and consistency checks maximised the chances of detecting information gaps and inconsistencies in input from different people.

While the case study region of Mugello and Valdisieve was relatively small, the theoretically robust principles based on benefit:cost analysis, and which consider a range of technical, social, economic and political factors (Pannell et al., 2013), suggest that the framework is likely to also be useful in other areas in Italy and Europe. No modifications to the framework were required. Furthermore, the relatively mature regulatory framework operating in the EU based on region-specific rural development plans already caters for institutional and geographical heterogeneity. We thus conclude that INFFER shows the potential to support the design of public investment programmes for the management of agro-environmental resources at the local level. Natura 2000 is likely to be the most readily compatible programme, already having a network of clearly defined and spatially-specific protected areas.

A few difficulties were encountered when applying INFFER; dealing with identification of assets and deciding the $V$ value were the most problematic. People involved often found it difficult to be spatially-specific in defining agro-environmental assets, particularly land assets and assets representing connectivity of agro-ecosystem units (e.g. agro-ecosystem continuity and ecological infrastructure networks). This was partially due to the fact that, in the case-study areas, land units were highly scattered and geo-referencing of agro-ecosystem parcels and connectivity was complex. The problem of people understanding the importance of being sufficiently spatially-specific has also been found in Australia. Regarding the attribution of $V$ values, assigning values to environmental assets is a regular cause for concern to those involved people, particularly ecologists. The INFFER $\mathrm{V}$ table is a very simple way to value assets and is certainly likely to be contested. This is not only a problem of INFFER, but rather a much bigger problem associated with environmental valuation in general. INFFER uses a deliberately simple approach because there are potentially large numbers of assets that are candidates for investment. Furthermore, as shown in the BCR, the asset value is only one of a number of factors that need to be considered. Our preliminary attempt at ranking some of Tuscany's valuable assets might serve as a prompt for greater discussion about environmental valuation approaches in general. The reality is that decisions are already being made about what to protect, but the

Table 7. Sensitivity analysis of $P$ and $G$ coefficients for values respectively higher and lower than the selected actual values.

\begin{tabular}{|c|c|c|}
\hline \multirow[t]{2}{*}{ Coefficient } & \multicolumn{2}{|c|}{ Benefit-cost ratio } \\
\hline & S. Brigida & S. Antonio \\
\hline \multicolumn{3}{|c|}{ Coefficient including socio-political risk (P) } \\
\hline $\mathrm{P}=0.37$ & 1.19 & n.c. ${ }^{*}$ \\
\hline $\mathrm{P}=0.62$ & $2.00^{\circ}$ & n.c. \\
\hline $\mathrm{P}=0.85$ & 2.74 & 2.89 \\
\hline $\mathrm{P}=0.97$ & n.c. & $3.30^{\circ}$ \\
\hline \multicolumn{3}{|c|}{ Coefficient including risk related to long-term funding (G) } \\
\hline $\mathrm{G}=0.1$ & 0.67 & n.c. \\
\hline $\mathrm{G}=0.3$ & $2.00^{\circ}$ & n.c. \\
\hline $\mathrm{G}=0.5$ & 3.33 & 2.36 \\
\hline $\mathrm{G}=0.7$ & n.c. & $3.30^{\circ}$ \\
\hline $\mathrm{G}=0.9$ & n.c. & 4.24 \\
\hline
\end{tabular}

environmental value assumptions are not transparent.

Questions remain as to whether INFFER can be applied on larger scales in the EU or its suitability for other agro-environmental programmes. Given the European Court of Auditors (2011) report, there is certainly a need for a bigger focus on environmental outcomes. For such programmes, INFFER addresses many of the issues highlighted in the Auditors' report. These include the need for sufficiently specific objectives, providing clear justification for current agro-environmental payments on the basis of environmental pressures, being clear about the environmental benefits achieved, a need for increased targeting, and greater use of evidence to support management decisions.

In addition to being able to provide a transparent way to compare the cost-effectiveness of projects and potentially demonstrate environmental outcomes, we found several other strengths of INFFER over current processes: i) the involvement of local stakeholders in the process of agro-environmental asset identification; ii) a transparent and objective process to select assets; iii) the combination of quantitative analysis and simplified procedures for practical applications.

Challenges posed by INFFER include the possibility of requiring more time than with current processes because the information is highly context-specific. Performance monitoring against set goals also has the potential to be more resource-intensive than current processes. These concerns were also raised in Australia when people start using INFFER. These challenges can be managed by critically thinking about which of the current administrative processes are not contributing to an outcome focus; recognising that some of these are not required would reduce the problem.

Overall, our conclusion is that INFFER is both relevant and useful in the EU. It appears to be highly compatible with Natura 2000. There is increased pressure on governments to achieve more cost-effective outcomes for agro-environmental asset protection and there are few (if any) developed alternatives to help achieve cost-effective outcomes at the design stage. Testing of INFFER in a variety of EU situations, and assessing its suitability in other agro-environmental programmes, would be well worthwhile.

\section{References}

Alexander JK, Roberts AM, Panell DJ, 2010. Victorian catchment management approaches to salinity: learning from the National Action Plan experience. Austr. J. Environ. Manage. 17:42-52.

Buytaert V, Muys B, Devriendt N, Pelkmans L, Kretzschmar JG, Samson $\mathrm{R}, 2011$. Towards integrated sustainability assessment for energetic use of biomass: a state of the art evaluation of assessment tools. Renew. Sustain. Energy Rev. 15:3918-33.

Cashmore M, Gwilliam R, Morgan R, Cobb D, Bond A, 2004. The indeterminable issue of effectiveness: substantive purposes, outcomes and research challenges in the advancement of environmental impact assessment theory. Impact Assess. Project Appraisal 22:295310 .

Chadwick A, 2002. Socio-economic impacts: are they still the poor relations in UK environmental statements? J. Environ. Plan. Manage. 45:3-24.

Cooper T, Hart K, Baldock D, 2009. The provision of public goods through agriculture in the European Union. Report prepared for DG Agriculture and Rural Development, Contract No. 30-CE0233091/00-28. Institute for European Environmental Policy, Brussels, Belgium.

European Commission, 2007. Agriculture in the European Union Statistical and economic information. European Commission, Brussels, Belgium. 
European Commission, 2012. Rural development in the European Union. Statistical and economic information. Report 2012. European Commission, Brussels, Belgium, p 370. Available from: http://ec.europa.eu/agriculture/statistics/rural-development/2012/ full-text_en.pdf

European Court of Auditors, 2011. Special Report No.7/2011. Is agrienvironment support well designed and managed? European Union, Luxembourg, p 75. Available from: http://eca.europa.eu/portal/pls/portal/docs/1/8772726.PDF

European Network for Rural Development (ENRD), 2013. Rural development policy in figures. European Network for Rural Development, Brussels, Belgium (EU). Available from: http://enrd.ec.europa.eu/policy-in-action/rural-development-policyin-figures/en/rdp-figures_en.cfm Accessed: 25 Feb 2013.

Grossoni P, Venturi E, 2009. Il Cisto laurino di Santa Brigida. Regione Toscana, Provincia di Firenze, Comune di Pontassieve, ANPIL Poggio Ripaghera, Santa Brigida, Valle dell'Inferno, Firenze, Italy. [in Italian].

Institute for Environmental Studies (IVM), 2006. Sixth EU framework programme for research and technological development, sustainabilityA-test project. Available from: http://www.sustainabilitya-test.net/

Kørnøv L, Christensen P, Nielsen EH, 2005. Mission impossible: does environmental impact assessment in Denmark secure a holistic approach to the environment? Impact Assess. Project Appraisal 23:303-14.

Lampkin N, 2011. Relevance of OECD agri-environmental measures for PES. In: D. Ottaviani and N. El-Hage Scialabba (eds.) Payments for ecosystem services and food security. FA0, Rome, Italy, p 281.

Nilsson M, 2006. Sustainability appraisal tools. In: Institute for Environmental Studies (ed.) SustainabilityA-Test. Sixth EU framework programme for research and technological development,
sustainabilityA-test project. Available from: http://www.sustainabilitya-test.net/

Noble BF, 2004. Strategic environmental assessment quality assurance: evaluating and improving the consistency of judgments in assessment panels. Environ. Impact Assess. Rev. 24:3-25.

Organisation for Economic Co-operation and Development (OECD), 2010. Guidance on sustainability impact assessment. OECD, Paris, France.

Pannell DJ, Roberts AM, 2010. The Australian national action plan for salinity and water quality: a retrospective assessment. Austr. J. Agric. Resour. Econ. 54:437-56.

Pannell DJ, Roberts AM, Park G, Alexander J,. 2013. Designing a practical and rigorous framework for comprehensive evaluation and prioritization of environmental projects. Wildlife Res. 40:126-33.

Pannell DJ, Roberts AM, Park G, Alexander J, Curatolo A, Marsh S, 2012. Integrated assessment of public investment in land-use change to protect environmental assets in Australia. Land Use Policy 29:37787.

Regione Toscana, 2012. Programma di sviluppo rurale della Regione Toscana (versione 9 in vigore dal 17/7/2012). Regione Toscana, Firenze, Italy.

Schomers S, Matzdorf B, 2013. Payments for ecosystem services: a review and comparison of developing and industrialized countries. Ecosystem Services [In Press].

Studio D.R.E.A.M. Italia, 2004. Piano di gestione del complesso forestale regionale Foresta di Sant'Antonio. Giunta della Regione Toscana, Deliberazione n. 472 del 24/05/2004.

Vannuccini M, 2011. Piano di gestione delle formazioni vegetali dell'ANPIL Poggio Ripaghera, Santa Brigida, Valle dell'Inferno. Comune di Pontassieve, ANPIL Poggio Ripaghera, Santa Brigida, Valle dell'Inferno, Firenze, Italy. 